\title{
Montenegro in the PISA Study
}

Saša Milić ${ }^{1}$

$\approx$ Montenegro, a country that has been in transition for the last two decades, is trying intensively to restructure its socioeconomic system and reform the main social systems, such as the education system, health care, the judicial system, the social welfare system, etc. Numerous strategic documents have been adopted in the past decade emphasising the importance of making the country's abundant natural resources functional, and of making the utilisation of human resources in the country significantly more effective. In order to achieve improvements in one of the key areas of Montenegrin development, human resources, a reform of the entire education system was launched in the first years of $21^{\text {st }}$ century. The processes of joining the European Union, whose fundamental principles are the free movement of people, goods, services and capital, have also significantly increased the need to raise the quality of the education of Montenegro's citizens and to improve the competitiveness of the Montenegrin workforce in the labour market. However, we believe that the results of PISA testing in 2006 and 2009 suggest that Montenegro is far from the proclaimed goals of reform in the field of education, and that for the coming years and decades considerable attention should be devoted to improvement of the education system. PISA tests should be understood in a much wider context, not only as a reflection of curricular reform and standards of verification and assessment of students' knowledge, but rather as a set of guidelines that indicate the direction in which to develop and improve the education system, so that society can really 'invest' in the education of young people.

It is a very problematic fact that from the time of testing in 2009 until April 2011, nobody in Montenegro published any technical or scientific analysis of the success, or rather failure, of Montenegrin students in PISA testing. We believe that the use of this study should be significantly increased; not for comparing academic achievements with those of students from other countries, but primarily for improving educational

1 University of Montenegro - Faculty of Philosophy 
policy and defining the strategic orientation of the development of the education system in Montenegro. Therefore, the absence of analysis implies an absence of certain professional activities focused on training teachers and improving the quality of students' knowledge.

Keywords: Achievements, Assessment, Functional knowledge, Improvement, Quality of teaching and learning

\section{Introductory analysis}

Montenegro, as a country that has been in transition for the last two decades, is trying intensively to restructure its socioeconomic system and reform key social systems, such as the education system, the health system, the judicial system, the social welfare system, etc. A number of policy documents adopted in the past decade have highlighted the importance of improving functionality in the country's natural resources, as well as of making significantly more efficient use of the country's human resources. In order to improve one of the key elements in the development of Montenegro, human resources, the first years of the $21^{\text {st }}$ century saw the launch of a reform of the entire education system. "With the intention of achieving more dynamic socioeconomic development, the most important factor is to ensure staff who have adequate knowledge and skills. This is an issue of national importance." (Basis for the Revision of Curricula, 2003, p. 6). EU integration processes, whose fundamental principles are the free movement of people, goods, services and capital, have also significantly increased the need to raise the quality of citizens' education and the competitiveness of the Montenegrin workforce in the labour market. However, we believe that the results of PISA testing in 2006 and 2009 indicate that Montenegro is still far from the proclaimed goals of reform in education, and that in the coming years and decades we will need to devote considerable attention to improving the education system. The PISA test should be understood in a wider context; not only as a reflection of curricular reform, scale testing and the evaluation of students' knowledge, but rather as a set of guidelines that show us the direction in which to develop and improve the education system, so that society can really 'invest' in the education of young people.

The quality of the Montenegrin education system is largely based on well educated teaching staff and their enthusiasm and will to invest their maximum in the education of children and young people. However, the social crisis of the 1980 os and 1990 os resulted in the disintegration of Yugoslavia, a number of 
armed conflicts and wars, economic recession accompanied by enormous inflation, and the collapse of society's value system. At the end of the $20^{\text {th }}$ century, Montenegro was focused on itself, its needs and how to open the way to independence. This orientation towards needs led to a better understanding of the situation in which the education system existed. Several pedagogical analysts in Montenegro, as well as international organisations and relevant educational authorities, came up with a similar list of problems in education when analysing the situation in the education system at the beginning of the $21^{\text {st }}$ century: 1 ) the weakened role of school integration, 2) the lack of school encouragement in students' motivation for learning and continuous intellectual development, 3) the lack of linkage between schools and local communities, 4) the lack of pedagogical education for parents, 5) the lack of professional competence and motivation of teachers for professional development, 6) the lack of professional autonomy and accountability of schools and teachers, 7) insufficient professional management education for directors, 8) the lack of methodological pluralism in the educational process, 9) the low quality of knowledge and insufficient capacity for full personal, social and work engagement, 10) the inadequacy of grading, 11) the lack of an adequate system of monitoring the implementation of educational programmes" (Milic, 2010, pp. 230-231).

In order to overcome these problems of the education system, in 2001, Montenegro began an extensive process of education system reform at all levels, through the adoption of the main strategic document, the "Book of Changes." This document laid the foundation for the transformation of the education system, which should respond to the numerous challenges of today, such as globalisation, Europeanisation, individualisation and the harmonisation of education systems. In addition, the education system should contribute to the development of Montenegrin society as an open and democratic society, a society based on economic prosperity and a workforce qualified for the needs of the modern labour market, and a society that equally respects individual rights and needs. All of these strategic goals are inevitably accompanied by the construction of an education system that should provide high quality teaching and learning at all levels. In the 2004/05 academic year, Montenegro commenced the implementation of reforms in 20 primary schools, and then successively included the remaining primary schools, up to total of 161 schools. The implementation of the reform processes in the secondary segment of the education system (grammar schools and secondary vocational schools) started later, in the 2005/06 and 2006/07 academic years. "Based on the student-centred teaching approach, the education system designed and implemented must rely on all of these principles, especially on the principle of choice according to individual 
abilities. By applying this principle, each student is given an opportunity to express his or her full potential. This way young people will be formed as responsible citizens who contribute with their activities to the democratisation of society. In order to enable students to progress according to their abilities and to satisfy their special interests, students at all levels of the system (from preschool to high school) are given choice, of a subject or part of a subject's contents, as well as of methods and forms of work, and also different strategies of learning. The aforementioned starting point of Montenegrin education reform (student-centred teaching), along with respecting the principle of individuation, has imposed the development of curricula based on learning outcomes. This means that they contain the objectives that students should achieve, as well as standards of required knowledge. In addition to the curriculum, in order to respond to the individual needs of children, it was necessary to modify the environment in which students spend time, and to intensify the use of different methods and forms of work through carefully planned activities for students. In addition, students were offered different textbooks, adapted to the new teaching approach and to the different sources of knowledge that students will, during primary and secondary education, learn to use" (Popovic, 2010, p. 165).

Education in Montenegro has always been a focus of interest for both the professional and general public, and therefore changes in the education system were extensively monitored. Expectations of education system reform were high but seldom unrealistic. "The modern knowledge society requires the student first to understand and learn how to study throughout life. The question is how to make learning more attractive to the student and not to let it become torture and an effort, but rather a need and a source of satisfaction" (Kotri, 2010, p. 420). However, it seems that the early effects of the reformed education system have not given the expected results, and that schools in Montenegro have failed to significantly raise the level of motivation and interest of students for learning and acquiring high-quality and functional knowledge. It also appears that the initial enthusiasm of teachers for introducing changes has decreased significantly, and that we are now at a turning point in the implementation of reforms, faced with the more difficult task of re-motivating teachers to implement reform solutions and raise the quality of the teaching process.

\section{Achievements of Montenegrin students in the 2009 PISA test}

A basic analysis of the results of testing conducted in 2009 indicates that Montenegrin 15 -year-olds are significantly below the OECD average, which is 
about 500 points out of a maximum 600. Montenegrin students' underachievement is more significant compared to leading countries: Shanghai-China, South Korea, Finland, Hong Kong, China, Singapore, Canada, New Zealand and Japan.

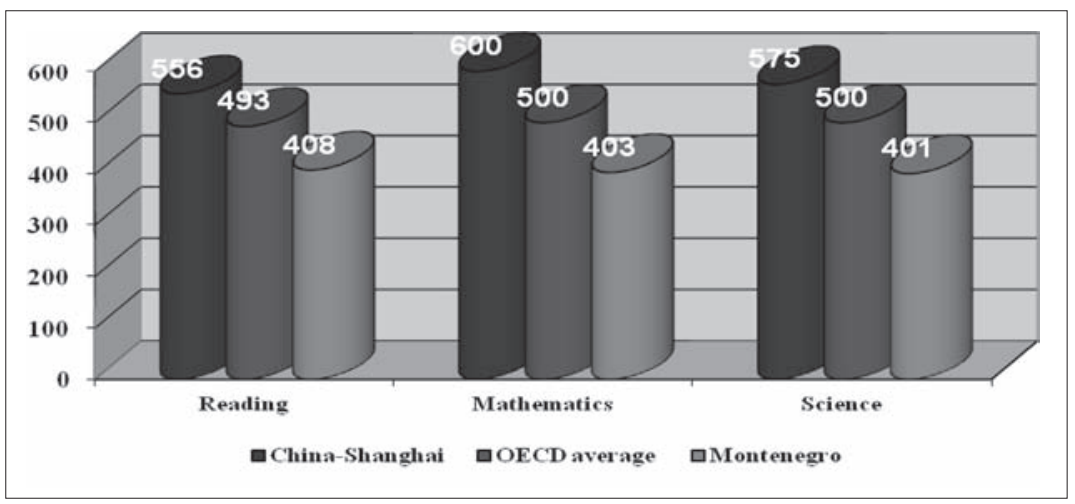

Figure 1: Achievements of Montenegrin students in the 2009 PISA test.

We believe that the results obtained by students from the best ranked countries could largely be the result of education policies that are substantially aligned with the statement that "the school, according to the revolutionary changes taking place around us, would have better results if dedicated to the equally risky, and perhaps equally quixotic, ideal of preparing students for coping with a changing world in which they will live" (Bruner, 200o, p. 9).

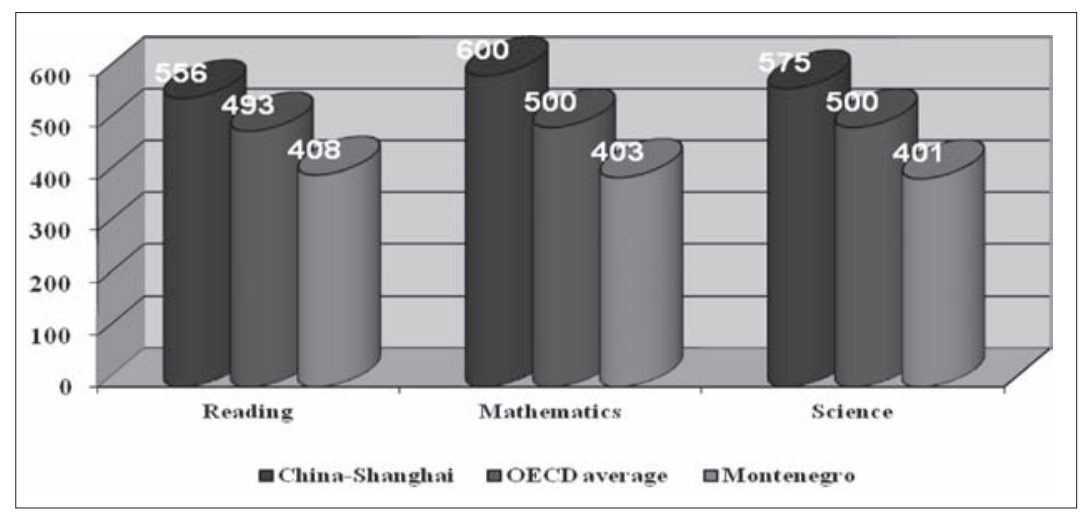

Figure 2: Results of Montenegrin students in PISA testing in 2006 and 2009.

Source: OECD studies from 2006 and 2009 (www.oecd.org/document) 
Although the number of countries participating in PISA testing in 2006 ( 57 countries) increased in the evaluation of students' academic achievement in 2009 (65 countries), we must conclude, with dissatisfaction, that Montenegrin students were ranked significantly worse than in the previous test. Thus, Montenegro decreased from $51^{\text {st }}$ to $54^{\text {th }}$ place in the reading literacy test, and from $49^{\text {th }}$ to $54^{\text {th }}$ place in the mathematics test, while the largest decline in terms of achievement was seen in children's tests of science, where there was a decrease from $48^{\text {th }}$ to $55^{\text {th }}$ place.

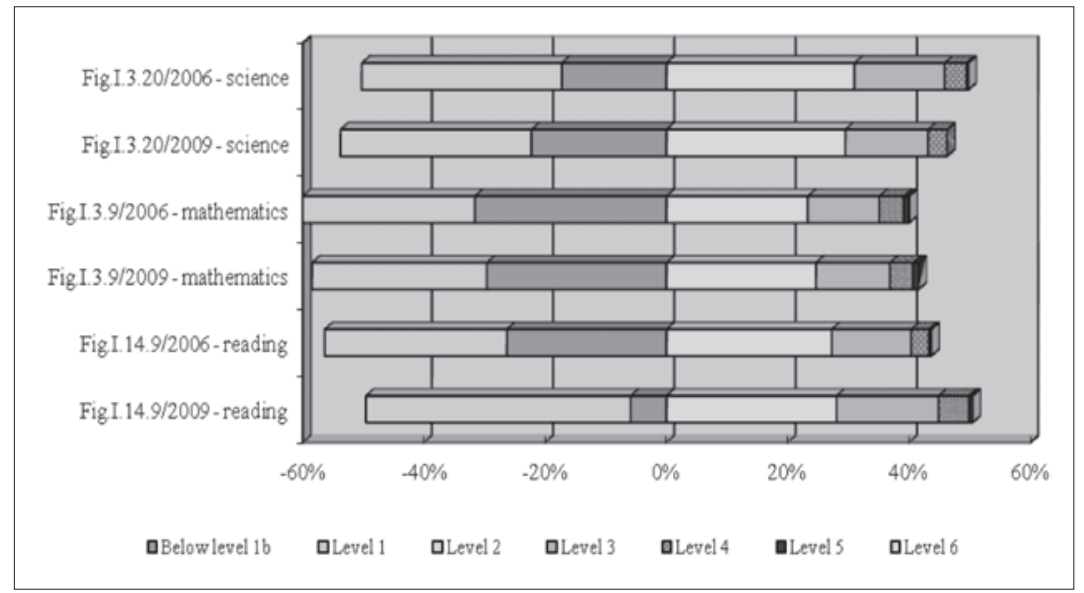

Figure 3: Summarised results of Montenegrin students in 2009 and 2006 in tests of reading literacy (fig.I.14.9), mathematics (fig.I.3.9) and science literacy (fig.I.3.20).

The special significance of the tests is reflected in achievements in reading literacy, due to the fact that reading literacy has a significant direct impact on overall student performance, on achievement in other subjects (apart from the native language), and on creating reading culture and training students for lifelong learning. "In addition, within certain tasks in the reading literacy of students they are asked to present their own opinion. Naturally, the question of whether schools in Montenegro provide sufficient space for students to express their own opinions, irrespective of the subject, with input to critically reflect on, express emotional experiences related to some content or text and to evaluate them. It is therefore necessary to pay special attention to reading, but also to the development of critical thinking and the child's speaking; for example, by raising adults' awareness of the importance of reading for the psychosocial development of children, by providing better access to books for children, by 
developing reading habits and motivation for reading, and by ongoing support to children in developing skills for reading literacy" (Petričević, Backović \& Ostojić, 2008). In the light of recognition of the importance of reading literacy for the overall intellectual development and academic achievement of students, the results that Montenegrin students achieved in the 2009 PISA test were very discouraging. In terms of the different categories of questions in the reading literacy test, Montenegrin students achieved the following results (Fig.I.2.20/2009 - access and retrieval of information in a text already read; Fig.I.2.23/2009 - the integration and interpretation of a text already read; Fig.I.2.26 / 2009 - reflection and evaluation of a text already read; Fig.I.2.32/2009 - the quality of reading in a continuous text; Fig.I.2.35/2009 - the quality of reading in a non-continuous text):

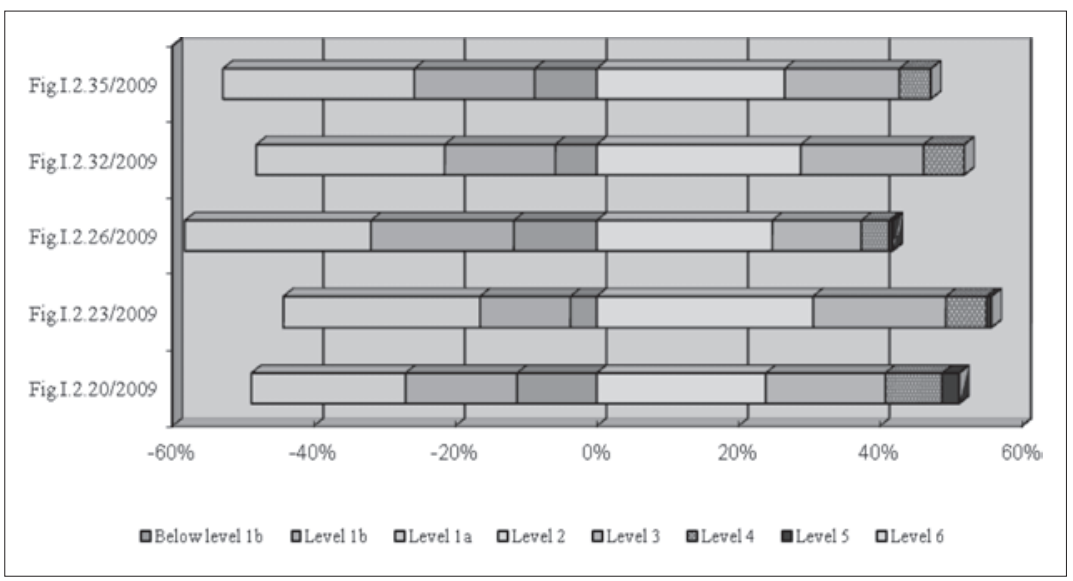

Figure 4: Achievements of Montenegrin students in the reading literacy test.

According to OECD classification, the achievements of Montenegrin students in the reading literacy test are in a category significantly below the OECD average, with the achievement of 408 points out of a maximum of 600 points. A significant increase in achievements in the 2009 reading literacy test was achieved by students from Turkey, Chile and Mexico, all of whom had been ranked behind their Montenegrin peers in previous tests. At the 2009 test, all EU member states and some South American countries, such as Uruguay, Trinidad and Tobago, Colombia and Brazil, achieved better results than Montenegro. The reading literacy test showed that enjoyment in reading is an important factor for the improved achievement of Montenegrin students. Accordingly, those who enjoy reading scored the highest average of 457 points, while those who enjoy reading less 
scored an average of 379 points. The amount of time spent reading also determines achievement. Those students who read for 1-2 hours per day achieved an average score of 427.8 points, while those who read up to half an hour per day achieved an average score of 383 points. Daily online reading also has a positive effect on the achievement of Montenegrin students in the reading literacy test. Students in the top quarter in terms of time spent reading online achieved an average score of 416 points, while those from the lower quarter, who read online very little, had an average score of 379 points. In terms of the relationship between awareness of the importance of links between understanding and remembering information, on the one hand, and achievements in the reading literacy test, on the other hand, it has been shown that Montenegro is in the category with countries whose students have a below average developed awareness of the importance of such strategies (compared to the OECD average), which resulted in below average achievements in the test (mean index -0.28). Significant disparities appear among Montenegrin students in this regard: those from the upper quarter have an average score of 423 points, while those from lower quarter have an average score of 388 points. There is a negative correlation in terms of students' awareness of the importance of effective strategies in summarising information and achievements in the reading literacy test. In this regard, Montenegro was in the same group as countries such as Indonesia, Jordan and Kazakhstan (which is common), and there is a very strong negative relationship between below average achievement in the test and a below average level of student awareness of information summarising strategies (mean index -0.57). It is with regard to these grading criteria that one of the most drastic differences among Montenegrin students is evident, with those in the upper quarter achieving an average score of 457 points, while those in the lower quarter have an average score of only 378 points. Knowing that 40 points in the test represent about the same quantum of knowledge acquired in a school year, we can conclude that the underdeveloped strategies of summarising information result in students falling behind in the reading literacy test to the extent of more than two school years. The inefficiency of the storing and mechanical memorisation of material has long been recognised by educational theory and practice, and the achievements of Montenegrin students in this test confirm this. In fact, it turned out that Montenegrin students achieve a negative score of -14.5 points per unit of storage; put simply, the more students learn through mechanical memorisation, the worse their achievement in the test becomes. A significant departure from the achievements in relation to the OECD average in the reading literacy test emerges when it comes to girls from Montenegro, who are in the large-scale category. Those who read tests give us the right to question the objectivity of statements about enjoyment in reading, as, given the large percentage of those who enjoy reading, one 
would expect accomplishments in the test to be significantly higher. Sexual Gender differentiation in this respect is also expressed in Montenegro, and Montenegrin boys are significantly closer to the OECD average of $71.5 \%$ of those who enjoy reading, while girls far exceed the Montenegrin average, with $87.3 \%$ of them stating that they enjoy reading. Such statements by Montenegrin students give quite an unrealistic picture of themselves and their learning process. There are similar discrepancies in terms of links between the socioeconomic status of students and the enjoyment of reading. Thus the lower quarter of Montenegrin students according to socioeconomic status enjoy reading in $76.5 \%$ of cases, while the upper quarter by this criterion enjoy reading in $80.9 \%$ of cases. The PISA study has shown that in Montenegro there is a positive correlation between the socioeconomic status of students and income inequality, with this increase in disparity resulting in poorer achievement of students, a fact that was shown deeply and broadly. Girls represent $45.9 \%$ in this category (OECD average $49.5 \%$ ), while Montenegrin boys from this category are very close to achieving the OECD average with $38.4 \%$ (OECD average $38.7 \%$ ). According to the results of the student questionnaire, $79.2 \%$ of students in Montenegro read for enjoyment, which is significantly above the OECD average of $63 \%$. Despite their below average achievement in reading literacy, the percentage of variance in reader achievement related to various aspects of family heritage (such as level of parental education, cultural heritage and the number of books at home, resources for home education, wealth, single parenting, family immigration status or a combination of these aspects) is significant and could affect an almost 20\% higher achievement if these aspects were positive. Employment of the students' mothers emerged as an important prerequisite for improved success in reading literacy tests, as students whose mothers work achieved significantly better test results in reading literacy ( 428 points).

An interesting result of the PISA study indicates that the location of schools in Montenegro does not have a significant influence on the reading literacy of students. The average achievement of students in towns and villages with fewer than 3,000 inhabitants was around 390 points, while the average achievement in Podgorica, Montenegro's only city with more than 100,000 inhabitants, was about 413 points. Although there certainly is a difference, it is not as large as is often claimed by the Montenegrin professional community. According to the research criteria, Montenegro belongs to a small groups of countries, such as Sweden, Norway, Estonia etc., where the range of student achievement between villages and towns is relatively small. The biggest gaps in the achievement of urban and rural students are in Hungary, Bulgaria, Kyrgyzstan and Panama, where the difference is more than 80 points, while the OECD average is 40 points in favour of city children. 


\section{Analysis of the possible failure of Montenegrin students}

A common thesis in pedagogical theory in the countries of Central and Eastern Europe is that the system of teacher education in post-socialist countries was one of the most traditional and conservative systems, and that reform was not easy undertaken. In the PISA tests, this was shown to be only partly correct. For many decades, teacher education in these countries was oriented only towards lectures, the frontal method of work, preparing students for formal and rather rigid assessment of student achievement. The focus was on students' academic achievements to a significantly greater extent than in the interactive process of teaching and learning, and the results that students of different countries in this group achieve are very high; for example, in the reading literacy test of students from Estonia they achieved $13^{\text {th }}$ place, while students from Poland achieved $15^{\text {th }}$ place. It should also be noted that a significant number of countries from this group, including Hungary, Latvia, Slovenia, the Czech Republic and Slovakia, are within the range of the OECD average, or only slightly below it. In the Montenegrin system of higher education for teachers, we have made "the most massive changes regarding higher education teaching staff, and the foundation of the study programmes of pedagogy and psychology at the Faculty of Philosophy. The education of teaching staff has been raised from a high to a higher level of education (VII degree) in order to properly respond to the continuously growing needs of early education and further professional education for working with preschool children. Of special significance in the further development of the education system of Montenegro is the foundation of pedagogical and psychological studies, as key areas in the higher education of teaching personnel... Significantly fewer changes and less innovation have been applied to the higher education of teachers and subject teachers (languages, science, history, geography, art), and we can speak more of the rearrangement of the old curriculum in the education of teachers, rather than of substantive changes and improvement. A particular problem is the lack, or complete absence, of the pedagogical-psychological and didactic education of expert teaching staff in specialised teaching" (Milic, 2010, p. 233).

Many reform documents have noted that not enough attention is paid to initial motivation in the education of young people, and that they are often discouraged; however, we can conclude that the educational process in Montenegrin primary schools is still burdened with anachronous organisation, a lack of pedagogical stimulation of students and still very present excessive workloads. The main disadvantages of the curriculum in the Montenegrin education system are: the lack of methodological pluralism in the educational process; the 
inflexibility of the overloaded curricula; the lack of linkage between knowledge and the neglect of multi-disciplinary and interdisciplinary knowledge; the low level of knowledge and insufficient capacity for complete personal, social and work engagement; the lack of an adequate system of monitoring and implementation of curricula; and the lack of adequate material and technical conditions for the implementation of programme requirements. So far, no extensive scientific research on the effects of the curricular reform has been undertaken, and it is therefore difficult to state with any sureness the extent to which the above mentioned disadvantages have been removed. However, the results of the PISA test still suggest that Montenegrin teachers are still not inclined to accept the simple pedagogical strategy that the goal of teaching is not the breadth but the depth of the material. "The curriculum of the reformed primary school, compared to the unreformed curricula, set different, modern educational trends and developments in the world. Three cycles were introduced - at the end of the third, sixth and ninth grades - and the objectives at the end of each cycle were defined. Through educational programmes, horizontal and vertical representation and connectivity of key areas was provided, sometimes as individual curricula and sometimes as thematic units related to the existing curriculum. Whenever it was possible, correlation between subjects and alignment and positioning of intersubject areas was built. The curriculum is designed to leave enough space for the required elective courses through which students meet their interests in certain fields. In parallel with changing curricula, new textbooks were made in order to follow the new curricular reform and solutions, offering, for the first time for some subjects, especially in lower grades, manuals for teachers with methodological recommendations for the implementation of the programme provided topics in the textbook" (Jacimovic, 2010, p. 64). The basis of nine-year primary education is partially an open type of curriculum, unlike the closed curriculum that was used in Montenegrin schools before, and there has been a transition from teaching to a target curriculum where learning outcomes are important, which represents one of the most important innovations of the reformed primary school. Programmes do not contain 'lessons', but rather topics that are conceived according to defined standards of knowledge and skills, to which the teacher must lead students using a more flexible system of learning, teaching and access, leaving the teacher room to choose the way, methods and assets that will lead students to the defined standard. The new reform solutions have changed the role of teachers in the learning process, but they have also particularly redefined the role of students; the student is transformed from a passive listener to an active participant in the process of acquiring knowledge, a role that the new programmes clearly recognise through 
the envisaged activities of students. Teachers therefore become more active in the preparation of materials for teaching and take on the role of 'moderators' leading the children to achieve the standards. All of this is planned by the reform documents, but it seems that many questions still remain open regarding the curriculum. Although the new curriculum recommends vertical and horizontal curriculum correlation, the reality is that the Montenegrin educational process is often characterised by the absence of an interdisciplinary approach to knowledge and, consequently, the inability of Montenegrin students to combine material from different subject areas.

Dysfunction and a lack of solidity in the knowledge of Montenegrin students is certainly one of the key challenges of the Montenegrin education system. We believe that the education system still 'suffers' significantly from a lack of clear linkage between school knowledge and real life, i.e., the application of acquired knowledge in everyday situations. We can completely agree with the attitude of the famous German pedagogue, Hartmut von Hentig, who on a list of ten deficiencies in reform states that "school reform must go further (i.e., to be more radical) ... and the school has to become for children a place of life where you gain experience relevant to the existence of this world" (Hentig, 1997). We believe that in the case of curricula in Montenegro this remained a major problem after the introduction of the new reform solutions. In fact, PISA tests show that the Montenegrin curriculum still pays very little attention to the applicative value of knowledge, i.e., the adoption of functional knowledge.

There is an incapacity for critical thinking, as in the learning process the development of Montenegrin students' problem solving ability is not encouraged. This claim is fully supported by surveys conducted among students after the PISA test, as well as later impressions of students about their achievements. The students themselves assessed that their achievements in the PISA tests were unsatisfactory. In their opinion, the results are low because in primary school they learned mostly by heart; furthermore, they have not learned to use logic and they are generally taught "unnecessary things", with an emphasis on theory rather than practice, especially in the subjects of physics, chemistry and biology. The general students' conclusion about the failure in PISA testing is contained in their attitude: "it turned out that we have been taught incorrectly."

The process of training teachers to implement reform solutions in the education system took place in parallel with the introduction of changes in educational institutions in the 2004/2005 school year. However, despite the fact that in the period from 2000 to 2008 some 5800 teachers and 200 directors of educational institutions were trained and over 350 seminars were organised, we believe that the reasons for the unsatisfactory achievement of Montenegrin 
students in the PISA test can be sought in the insufficient and inadequate training of teachers. First of all, we believe that the training period was inadequate, with a large number of teachers only undertaking one or two three-day training sessions. The competent ministry departed significantly from its own initial determination on the importance of the professional development of teachers. All of the relevant studies on the effects of professional development suggest that "only the persistent, consistent and long-term application of innovation efforts in the education system can lead to its permanent foundation and acceptance by the teaching staff and systems in general" (Milic, 2002). Despite these findings, the ministry withdrew the intensive professional training of teachers and the entire initial training for the implementation of new, reform solutions was reduced to only three days of training. Even today, the ministry has almost completely abolished external professional development in the form of seminars, instead introducing so-called internal training at the school level, which means interpersonal teacher training in the school and peer learning. The reasons for the lack of preparedness of teachers to improve teaching can be found in a significant number of conservative teachers who do not accept change. "A significant number of teachers have an evident traditionalist-conservative consciousness that is sceptical towards any innovation and change in the existing situation" (Damjanovic, 2001). The unwillingness and lack of openness of the teaching staff regarding the changes is shown by the following research findings: "Teachers of elementary school education and learning are treated primarily as a phenomenon and the monopoly of childhood and adolescence, but not adulthood and life in general" (Todorovic, 2002). Besides the above mentioned problems related to the quality of teachers, it is important to emphasise the inadequate financial motivation of teachers. Although, as early as in 2005, the relevant ministry adopted the "Regulation on Improved Teaching Positions," whose primary purpose was to expedite the improvement of teaching practice in schools and to identify those teachers who invest considerable efforts in their own professional development and quality of teaching, the application of the rules has not occurred in practice. The ministry justified the non-application of this regulation with various pretexts related to the need for its further treatment; however, it seems that the main reason was insufficient recognition of the importance of motivating teaching staff on the part of the ministry, as well as a failure to provide funding to ensure an increase in teachers' salaries in line with the revised titles (teacher-mentor, teacher-counsellor and teacher-researcher). In addition, it should be noted that "the material position of teachers seriously affects the quality of work and the commitment of teachers to introducing innovations in their work. This is reflected in the 
quality of teaching and learning. Low salaries are a serious obstacle to the implementation of the planned reforms" (Damjanovic, 2001). Although this assessment of the Deputy Minister of Education and Science of Montenegro dates back to 2001, the facts indicate that the level of teaching staff salaries is still not significantly higher, and that this type of obstacle to the implementation of reform solutions is still significant. In addition to the above, it should be noted that there is an almost complete lack of training sessions or minimal training of teachers in advanced elementary school classrooms and in secondary schools for the application of the principles of interactive teaching and the development of critical thinking in students.

As one of the reasons for the unsatisfactory success of Montenegrin students, the responsible personnel in the Examination Centre of Montenegro also state a lack of motivation for testing. Given that the PISA test is not obligatory in terms of the formal assessment of each student individually, and that it has no impact on overall success in school, it was noted that some students have an insufficiently serious attitude towards PISA testing and other forms of external tests that do not have direct consequences for formal assessment. It is particularly important to draw attention to the negative trend in the Montenegrin education system in terms of priorities. Specifically, the relationship of Montenegrin students towards the PISA test clearly indicates that students absolute priority is their grade, not their knowledge; accordingly, testing with informal effects on individual student achievement and assessment does not attract their attention. In view of this possible cause of the poor results of Montenegrin 15-year-old students in international testing, we believe that it can be concluded that there is an absence of national/state consciousness amongst students and a low awareness of the need for the quality presentation their own country through better achievements in PISA testing. It should be added that the promotional campaign about the importance of PISA testing is relatively limited. In fact, it seems that, apart from the Examination Centre of Montenegro as a referent institution for PISA testing, other institutions of the system, especially educational institutions, have done little to promote the importance of PISA. Students themselves often state that they were not prepared for testing at all; nobody worked with them on preparation for testing seven days prior to the realisation of the test. One of the common opinions of participants about the reasons for the failure in PISA testing is that this generation of young people are only concerned about how to finish school, regardless of the quality of knowledge acquired and regardless of what awaits them in the future with such superficial knowledge. An observation of the responsible personnel from the Examination Centre of Montenegro on the implementation of PISA tests in 
one high school clearly indicates a very low level of student motivation: it was noted that in the school over $50 \%$ of the students opened up the tests, looked at them, concluded that they were too difficult, and 15 minutes after the test began handed the test papers back having filled in almost nothing. The PISA test is not the only example of the lack of motivation of students to acquire knowledge; the numbers of justified or unjustified absences from school indicate a trend of increasing student absence from school, especially from natural sciences and mathematics classes. Responsible personnel from the Examination Centre of Montenegro attribute the lack of students' interest in achieving better results in the PISA test to their being unaccustomed to the use of standardised tests. In fact, it turned out that $37 \%$ of Montenegrin schools do not use standardised tests of knowledge, while this percentage in countries with better success in PISA tests is below $20 \%$. We largely agree with the view of the Austrian education theorist, Liessmann, who emphasises that "children whose reading skills are weak eloquently lamenting in this way after each PISA test does not improve reading; what is needed is 'motivation' and self-regulated learning, and in some schools 'motivation' has become a school subject. Probably in this class you learn how to be motivated for nothing. It is frightening that these concepts of practical pedagogical nihilism do not scare anybody" (Liessmann, 2009, p. 31). However, we believe that Montenegrin students' motivation to acquire knowledge in various fields is at an unacceptably low level.

The formalisation of continuous assessment in the regular teaching process is undoubtedly one of the major causes of failure in PISA testing. In fact, for over a decade there has been a tendency towards extremely superficial and unfounded assessment of student academic achievement in the education system. According to the formal success of Montenegrin students, Montenegro should be drastically better ranked in PISA testing, because all generations have a high percentage of excellent students, and it is not rare for this percentage to exceed $50 \%$ of the total population. The number of Luca 1 (all excellent grades in primary education) and Luca 2 (all excellent grades in primary and secondary education) student awards handed out indicates that Montenegro should be ranked significantly better than it is in international testing. This clearly shows very little predictive value in assessing the objectivity of the Montenegrin education system.

Pilot projects of inclusive education in the education system of Montenegro have been implemented in 2004 preschools and about 10 primary schools. Although the results of the implementation in these educational institutions are satisfactory, we believe that the achievement of students with disabilities is significantly below average, and this is reflected in the overall achievement of 
Montenegro's 15-year-old children in PISA testing. In fact, there are significant problems with the dissemination of the idea of inclusive education in the entire education system, especially in the advanced grades of primary and secondary schools. The reason for this situation lies primarily in the lack of training of teachers for accepting children with special needs, and the insufficient training of teachers for democratisation in the educational process and for respecting children's rights, as well as the fact that in many situations the relevant ministry has not complied with the needs of educational institutions that have children with special needs in terms of the adaptation of school buildings, thus limiting the number of classes and educational groups in which there are children with special needs. This view is confirmed by findings of the Bureau for Education indicating a lack of preparedness of teachers for inclusion. "Although most teachers agree that the new curricula is completely adapted to the age and abilities of individual students, nearly one fifth of them believe that they do not provide enough opportunities for the inclusion of children with special needs in education. One of the main causes of this discrepancy can be found in the fact that so-called individual educational programmes have not yet become a regular practice" ("Analysis of teaching goals and...", 2006). We have also observed a negative trend of teachers giving positive grades to students with special needs even though their achievements do not warrant such grades, a practice that teachers employ in order to avoid being subject to criticism.

In the Montenegrin education system, the issue of the education of gifted children is one of the least examined fields of pedagogical and psychological work, and it is a question to which little attention is generally paid in educational institutions. Therefore, it is no surprise that in PISA testing a very small percentage of Montenegro's 15-year-old students managed to pass level 2, clearly indicating a lack of continuous and systematic work with gifted students. We believe that some progress could be made in this area if the responsible personnel from the Bureau of Education of Montenegro, as the key institution for the creation of curricula, were to implement the planned review of standards in knowledge and examine whether current standards of knowledge really encourage students to develop a higher level of thinking.

The reform of the education system and new legal solutions in the field of education have sought to overcome the problem of the number of students per class; the maximum number of students per class is 30 , and in exceptional cases as high as 32, while the law does not define the lower limit, i.e., the minimum number of students in the classroom. "Almost all of the basic principles of the educational reform in our country are the basis for the introduction and true respect for the individualisation of the educational process. Applying the 
principles adopted, starting from the principle of democratisation of the system, including increased participation of local communities, citizens, their associations and parents in all educational change and its direct impact on the performance of schools and the educational process, through equal opportunities for all, according to which countries must guarantee equal rights to education for every individual regardless of gender, social and cultural background, religion, national origin, physical and mental constitution, etc. over flexibility, which implies that the system as a whole must be flexible, particularly regarding curricula and their openness, over interculturalisation as a way to prepare young people to live in a multicultural society, as well as training for the respect of values such as tolerance, peace, religious, racial and all other differences, provides the basis and creates an obligation for the introduction of individualisation in the teaching process" (Popovic, 2010, p. 171). Due to the objective impossibility of implementing the regulations and the evident lack of school space, as well as the total number of new school buildings, the legal imperative is often not respected and the number of students in major urban areas frequently exceeds the limit, reaching as many as 33-35 students per class, and sometimes even more. Such a large number of students in the class simply prevents quality work with all teachers and students, raising questions about the applicability of individualisation in the educational process, as one of the basic principles outlined by strategic reform documents.

\section{Final reflections}

The process of reform in the Montenegrin education system was launched in 2000/2001, and it should be noted that the main reform documents, such as the "Book of Changes" and the "Basis for the Revision of Curricula," are indisputably good quality strategic documents that are still topical. However, it appears that not enough has been done regarding the operational goals and objectives outlined in these documents, and that in the live teaching process we can still see the old dysfunctional elements of the educational process, with fewer elements of modern, interactive teaching being evident. In order to improve the quality of students' knowledge in the Montenegrin education system, and to achieve better results in the next PISA tests, the relevant institutions plan to publish a PISA 2009 National Report with recommendations for education policy makers, which should contain analysis of the student questionnaire and the school questionnaire, as well as analysis of student achievement in reading literacy, mathematics and natural sciences. Additional training is also planned for teachers working with tasks tested in PISA tests, with an emphasis on science and mathematics 
literacy. This will be supplemented by public campaigns regarding PISA testing, in order to raise the awareness and motivation of students, teachers, schools and society at large about the importance of this test (Jacimovic, 2010). According to representatives of the Bureau for Education, in the future, special attention should be focused on setting new goals for the process, insisting on procedural knowledge, along with the development of higher levels of abstract and critical thinking. Responsible personnel will be monitoring the system of schools, providing an external evaluation of each school once every four years, while leaving room for an internal evaluation at the school in the interim. However, according R. Novovic, an adviser from the Bureau for Education, the large time interval in external evaluation represents a large space for the unsatisfactory work of teachers and schools in general. Although the educational public emphasises that the results of the PISA test can serve educational policymakers and provide good indicators for assessing the quality of the education system, of concern is the fact that from testing in 2009 until now, April 2011, Montenegro has not published any technical or scientific analysis of the success, or rather the failure, of Montenegrin students in PISA testing. We believe that the use of this study should be significantly increased; not for comparing the academic achievements with students from other countries, but primarily for improving educational policy and defining strategic orientations for the development of the system in Montenegro. The absence of analysis implies the absence of certain professional activities focused on training teachers and improving the quality of students' knowledge.

One of the most important findings of PISA testing in Montenegro that should attract the attention of educational policy makers is the achievements of students who have attended preschool education. Montenegrin students who attended preschool education for between one and three years have average test results in reading literacy in the range of 516 to 521 points, while those who were at kindergarten for up to one year achieved results ranging from 496 to 505 points. Both of these results are equal to, or even above, the OECD average. This is a very good result, and it is encouraging in terms of the further endeavours of Montenegrin students to increase the level of knowledge acquired in the Montenegrin education system. It certainly provides a clear signal that the relevant authorities in Montenegro should do significantly more in the area of children in preschool education, as the coverage so far is around $27-28 \%$ of the total population of children aged from 1 to 6 years.

We believe that the argument put forward by representatives of relevant institutions (the Ministry of Education, the Examination Centre, the Bureau of Education) that the PISA tests so far have not included students who attend classes in the reformed educational process is difficult to support, and is simply 
an attempt to justify the low academic achievement of 15-year-old Montenegrin students. Given that the implementation of the reform started in the 2004/05 school year, it should be noted that by now all teachers (class and subject teachers - first to ninth grade) should have been included in the professional development of institutions outside schools, as well as in professional development at school level. This fact is confirmed by representatives of the Bureau for Education, the institution responsible for the professional development of teachers. In addition, the argument (or 'excuse') given is unacceptable due to the fact that in schools a subject teacher usually gives classes in different grades, from the fifth to the ninth grade; it therefore seems completely illogical to claim that in the fifth or sixth grades of primary school teachers are working to significantly improve the quality of development, including critical thinking, the quality of interpretation of knowledge, etc., while in the eighth and ninth grades (grades that provided the sample of 15-year-old students for PISA 2009) work takes place in an old-fashioned and conservative manner, a way that leads to passivity and students memorising material, resulting in the significantly low rating of Montenegro in the PISA test. We also believe that this argument is largely untenable due to the fact that school is a living organism that cannot simply be divided by a 'Berlin wall' into a reformed and unreformed part, and it is very unrealistic to claim that in one segment of primary school one can expect significantly better results, while in the second segment we have very bad results confirmed by PISA testing. The frequent opinion of representatives from relevant institutions who emphasise that it is not realistic for Montenegrin teachers to change the entrenched traditional mode of teaching 'overnight' and start working in a new, innovative way, is very serious and worrying. It seems unacceptable to refer to the period from 2001 to 2011 as 'overnight'. This argument further loses weight in view of the fact that most teachers now working with Montenegrin 15-year-olds have undergone some form of training for the implementation of reform solutions by working with students in lower grades of the third cycle (grades 7-9).

The systematic and long term view is that the failure of Montenegrin students in the PISA test has important implications for all segments of the education system, particularly at the secondary and higher education levels. The fact that Montenegro has substantially implemented the Bologna Declaration and its higher education system has been aligned with the basic 'Bologna' education principles will not be enough in itself to provide quality in higher education staff. It is unrealistic to expect that Montenegrin universities will have highachieving students to enrol in light of the poor results in the PISA tests in 2006 and 2009. Poorer knowledge gained at lower levels of the education system simply cannot be compensated for at the university level. This will inevitably lead 
to a lower level of knowledge of Montenegrin university graduates, and consequently a lower rating of higher education degrees obtained at Montenegrin universities. This trend will have a direct negative effect on the mobility of students and teachers, as well as negative consequences in terms of the employment of university educated people in Montenegro.

The state of reforms in the past, which was a condition that covered the education system over a period of several years, is now becoming a permanent condition. Due to the fact that "there are three indisputable facts on which education must rely in the world today, at the beginning of the $21^{\text {st }}$ century: the growth and strengthening of the multicultural movement, the global perspective of world problems and the stunning speed of overall technological development. All three of these facts change the nature, structure and objectives of education systems in the world" (Herrera \& Mandic, 1989).

The social changes that emerged from the disintegration of former $\mathrm{Yu}-$ goslavia - wars in neighbouring countries, the enormous increase in the refugee population (which at one point was close to $20 \%$ of the total population of Montenegro), drastic economic decline, etc. - have caused significant changes in the system of social values and the general social devaluation of moral norms. Accompanying this, there has been a process of debasement in values of knowledge, and the results of the PISA tests, unfortunately, support the idea that knowledge is still ranked very low on the scale of social values in Montenegro.

\section{References}

Analysis of Teaching and Program Goals in the First Cycle of Nine Year Elementary School Cycle -

Research (2006). Podgorica: Bureau of Education.

Bruner, J. (2000). Culture of Education. Zagreb: Educa.

Damjanović, R. (2002). The Essence and Dynamics of Change in the Education System of Montenegro. Education and Learning - Journal of Pedagogical Theory and Practice, (1).

Hentig, H. V. (1997). Humane School: School of Thinking in New Way. Zagreb: Educa.

Herrera, A., \& Mandić, P. (1989). Education for XXI Century - from Tradition to Revolution. Sarajevo:

Svjetlost.

Jaćimović, Ž. (2010). PISA 2009 - The Achievements of our Students in International Testing. Press Conference 7 th December 2010 - Podgorica.

Korti, Z. (2010). The Cultural Framework of our Educational System. In P. Vukotić (Ed.), Montenegro in XXI century - in the Era of Competitiveness: Education (pp. 417-426). Podgorica: Montenegrin Academy of Arts and Sciences.

Liessmann, K. P. (2009). The Theory of Lack of Education -The Knowledge Society Disabuses. Zagreb: Jesenski i Turk. 
Milić, S. (2002). The Individualization of the Educational Process. Podgorica: Pedagogical Center of Montenegro.

Milić, S. (2010). The Initial Education of Teachers in Montenegro. In P. Vukotić (Ed.), Montenegro in XXI century - in the Era of Competitiveness: Education (pp. 221-237). Podgorica: Montenegrin Academy of Arts and Sciences.

Basis for Revision of Curricula (2002). Podgorica: Ministry of Education and Science of Montenegro. Petričevič. I., Backović, A., \& Ostojić, T. (2008). National Report on Student Achievement in the International Testing Program for Students - PISA 2006. Podgorica: Ministry of Education and Science of Montenegro.

PISA 2009 Results: What Students Know and Can Do - Student Performance in Reading, Mathematics and Science - Volume I (2010). Paris: OECD.

PISA 2009 Results: Overcoming Social Background - Equity in learning Opportunities and Outcomes Volume II (2010). Paris: OECD.

PISA 2009 Results: Learning to Learn - Students Engagement, Strategies and Practices - Volume III (2010). Paris: OECD.

PISA 2009 Results: What Makes a School Successful? - Resources, Policies and Practices - Volume IV (2010). Paris: OECD.

Popović, D. (2010). Individualization in Teaching. In P. Vukotić (Ed.), Montenegro in XXI century - in the Era of Competitiveness: Education (pp. 161-184). Podgorica: Montenegrin Academy of Arts and Sciences.

Popović, D. (2010). Professional Development and Changed Roles of Teachers. In P. Vukotić (Ed.), Montenegro in the XXI century - in the Era of Competitiveness: Education (pp. 239-258). Podgorica: Montenegrin Academy of Arts and Sciences.

Todorović, K. (2002). School in the Concept of a Learning Society. Education and Learning - Journal of Pedagogical Theory and Practice, (4). 


\section{Biographical note}

SAŠA Milić, PhD, is Associate Professor at University of Montenegro, doctor of educational sciences. Member of National Education Council of Montenegro in two mandates and Chair of Department for General Pedagogy at Faculty of Philosophy, teaching following subjects at different departments: General Pedagogy, Contemporary Education Systems and Theories, Intercultural Pedagogy, Comparative Pedagogy, Education Policy. Author of five professional/scientific books and more than 50 articles published in scientific journals in Montenegro and abroad. Master Teacher Trainer in different innovative projects aimed to professional development of teachers, such as: ChildCentered Approach, Individualized Teaching, Cooperative Learning, Anti-bias in Education, Reading and Writing for Critical Thinking. 